\title{
İki Amaçıı Çoklu Gezgin Satıcı Problemi için Üç Aşamalı Çözüm Yaklaşımı
}

\author{
Beyza Günesen $^{1 *}$, Muzaffer Kapanoğlu ${ }^{2}$ \\ ${ }^{1}$ Eskişehir Osmangazi Üniversitesi, Mühendislik Mimarlık Fakültesi, Endüstri Mühendisliği Bölümü, Eskişehir, Türkiye (ORCID: 0000-0003-3709-7558) \\ ${ }^{2}$ Eskişehir Osmangazi Üniversitesi, Mühendislik Mimarlık Fakültesi, Endüstri Mühendisliği Bölümü, Eskişehir, Türkiye (ORCID: 0000-0002-8217-7517)
}

(International Congress on Human-Computer Interaction, Optimization and Robotic Applications (HORA) 2021 - 11-13 June 2021)

(DOI: $10.31590 /$ ejosat.952103)

ATIF/REFERENCE: Gunesen, B. \& Kapanoglu, M. (2021). İki Amaçlı Çoklu Gezgin Satıcı Problemi için Üç Aşamalı Çözüm Yaklaşımı. Avrupa Bilim ve Teknoloji Dergisi, (26), 325-331.

\section{$\ddot{O} \mathbf{z}$}

Çoklu gezgin satıcı problemlerinin (ÇGSP) çözümünde karşılaşılan güçlükler literatürde oldukça uzun bir geçmişe sahiptir. Çoklu gezgin satıcı problemi çalışmalarında etkin ve başarılı sonuçların tespiti ve tartışılabilirliği için iki tür ölçüt kullanılmaktadır. Bunlar tüm satıcıların kat ettiği toplam uzaklık veya herhangi bir satıcının kat ettiği en uzun mesafe olabilmektedir. Toplam uzaklık temel alındığında satıcılar arasındaki iş yüklerinde önemli dengesizlikler meydana gelmektedir ki bu istenmeyen bir durumdur. En uzun mesafeyi kat eden satıcının kat ettiği mesafe azaltılmak istendiğinde dengesizlik ortadan kalkmakta fakat toplam mesafe (maliyet) dengeyi sağlamak amacıyla artmaktadır. Problem üstel artan bir çözüm uzayına sahip olup NP - zor sınıfında yer almaktadır. Problemin eniyi çözüme ulaştırılmasında önerilen mevcut matematiksel modeller, günlük hayatta çok kısıtlı bir kullanıma sahiptir. Bu durum, pratikte ele alınan probleme özel çözüm yöntemlerini ön plana çıkarmaktadır. Bu bağlamda, üç servis aracı ile insan-topla-dağıt hizmeti yürüten bir işletmenin problemi üzerinde çalışılmıştır. Üçlü gezgin satıcı problemi, ÇGSP'nin satıcı sayısının üç olduğu hali olan bir alt kümesidir. Bu çalışmada, iki enküçükleme amacını da gözeten ve etkin çözümlerin kısa sürelerde elde edilebileceği üç aşamalı çözüm yaklaşımı önerilmiş olup, kümeleme ve rotalama olmak üzere iki ana adımdan oluşmaktadır. Kümeleme adımı, uğrak noktalarını yakınlıklarına göre k - ortalamalar yöntemi ile önce üç gruba ayırmaktadır. Elde edilen kümeler için rotalar başlangıçta En Yakın Komşu Sezgiseli (EYK) ile oluşturulmakta ve daha sonra 2-opt algoritması ile iyileştirilmektedir. Bu çalışmada önerilen yaklaşım çoklu gezgin satıcı problemi için kullanılan test problemlerinde ve rassal türetilen problemlerde uygulanmış ve sonuçlar matematiksel model sonuçları ile karşılaştırılarak ortaya konulmuştur. Herhangi bir satıcının kat edeceği en uzun mesafe, toplam mesafe ve algoritma çözüm süresi, performans ölçütleri olarak belirlenmiştir. Sonuç olarak önerilen ardışık yaklaşım, ilk ölçütte \% $70-80$ oranında en iyi çözümlere yakınsamış, diğer ölçütler de ise daha iyi performans sergilemiştir. Satıcılar arasındaki sapmaların ve toplam mesafenin paralel ödünleşerek enküçüklenmesi noktasında, elde edilen çözümler yüksek seviyeli olup, yaklaşımın koşma süresi polinom zamanlıdır.

\section{Three-Step Solution Approach for the Two-Objective Multiple Traveling Salesman Problem}

\begin{abstract}
The difficulties encountered in solving multi-traveling salesman problems (MTSP) have a long history in the literature. Two types of criteria are used to determine effective and successful outcomes and their arguability in multi-traveling salesman problem studies.
\end{abstract}

\footnotetext{
* Sorumlu Yazar: Eskişehir Osmangazi Üniversitesi, Mühendislik Mimarlık Fakültesi, Endüstri Mühendisliği Bölümü, Eskişehir, Türkiye, ORCID: 0000-0003-3709-7558, beyza.gunesen@,ogu.edu.tr
} 
These can be the sum of distances traveled by all salesman or the maximum distance traveled by any salesman. Significant imbalances occur in workloads between salesmen based on total distance, which is undesirable. When the distance traveled by the salesman who travels the maximum distance is desired to be reduced, the imbalance disappears, but the total distance (cost) increases to maintain the balance. The problem has an exponentially increasing solution space and is in the NP-hard class. The current mathematical models proposed for solving the problem at its optimum have very limited use in daily life. This brings to the fore the solution methods specific to the problem dealt with in practice. In this context, the problem of business management that runs people pick up and collect service with three vehicles has been studied. The triple traveling salesman problem is a subset of the MTSP where the number of salesmen is three. In this study, a three-phase solution approach, which considers both minimization objectives and which provides effective solutions in a short time, has been proposed. Clustering first divides the pick-up points into three groups according to their proximity with the k-means method. For the clusters obtained, the routes are initially created with the Nearest Neighbor Heuristic (NN) and then improved with the 2 - opt algorithm. The approach proposed in this study was applied to test problems used for the multiple traveling salesman problem and randomly generated problems, and the results were presented by comparing them with the results of the mathematical model. The maximum distance that any salesman will travel, total distance, and algorithm solution time are determined as performance criteria. As a result, the proposed sequential approach converged to the best solutions by $70-80 \%$ in the first criterion, outperforming other criteria. At the point where the deviations between salesmen and the total distance are minimized by parallel tradeoff, the solutions obtained are of high level and the running time of the approach is polynomial time.

Keywords: Multiple Traveling Salesman Problem, K - means, Nearest Neighbor, 2 - opt algorithm.

\section{Giriş}

Gezgin satıcı problemi (GSP) literatürde kendine önemli bir yer edinmiş bir kombinatoryal eniyileme problemidir. GSP'de amaç $\mathrm{n}$ adet şehrin her birinden yalnız bir kere geçerek başlanılan şehre geri dönme koşuluyla en düşük maliyetli yolu belirlemektir. GSP matematiksel anlamda ilk kez Karl Menger tarafindan 1930'lu yılların başında tanımlanmıştır. Simetrik ve $\mathrm{n}$ adet şehir içeren bir GSP için çözüm uzayı $(n-1) ! / 2$ turdan oluşmaktadır (Matai vd., 2010). Rotalama, üretim çizelgeleme, toplama dağıtma vb. gibi birçok gerçek hayat problemine kolaylıkla uyarlanabilmektedir. Problem yapısının kolayca anlaşılabilir olması buna karşılık çözüm uzayının büyüklügü sebebi ile çözümünün zor olması, sezgisel ve metasezgisel algoritmalara rahatlıkla uyarlanabilir olması ve gerçek hayat problemlerinde sıklıkla karşılaşılması gibi özellikleri içerisinde barındırdığı için araştırmacıların üzerinde fazlaca durduğu bir problemdir.

Çoklu gezgin satıcı problemi (m-GSP), bazı gerçek hayat problemlerinin klasik GSP ile modellenememesi sonucunda ortaya çıkmıştır ve klasik GSP'nin genişletilmiş bir versiyonudur (Carter, 2003). m-GSP'de bir satıc1 yerine m adet satıc1 mevcuttur. Tüm şehirler (n adet), m adet satıcı tarafından kapsanmalı ve her şehir tam olarak bir satıcı tarafından ziyaret edilmelidir. (Gilbert ve Hostra,1992). m-GSP, hangi şehirlerin hangi satıcılara atanması gerektiği kararını da içermektedir dolayısı ile GSP'den daha zor bir problem olduğu açıktır. Problem boyutunun büyümesi kesin çözüm yöntemlerinin kullanılabilmesi önünde büyük bir engel yaratmaktadır. Sezgisel ve metasezgisel algoritmalara duyulan ihtiyaç bu problemde de kendini göstermektedir.

Üçlü gezgin satıcı problemi (3-GSP), m-GSP'nin üç satıcının mevcut olduğu $(m=3)$ bir alt kümesidir. m-GSP uygulamalarının ilk örneklerinden biri olan baskı çizelgeleme probleminde (Goldstein, 1970) üç farklı baskı formu bulunmaktadır. Amaç, bir baskı çalışmasında hangi formun kullanılacağı ve ne kadar uzunlukta bir çalışmanın elde edileceğine karar vermektir. Bunun yanı sıra üç araçlı dağıtma - toplama, üç vardiyalı servis çizelgeleme gibi yaşamda birçok örneği olan uygulamalar, 3-GSP olarak karşımıza çıkmaktadır. Bu çalışmada da insan-topla-dağıt hizmetini içeren ve üç servis aracının bulunduğu bir sağlık işletmesinin problemi 3-GSP olarak ele alınmış ve bulgular, önerilen yöntemin m-GSP'ye genelleştirilebileceğini göstermektedir.

m-GSP çözümü için literatürde çoğunlukla metasezgisel yöntemler kullanılmış ve elde edilen çözümlerin etkinliği, yine aynı yöntemlerin birbirleri ile karşılaştırılması ile ölçülmüştür. ÇGSP için amaç fonksiyonları farklılık gösteren matematiksel modeller mevcuttur ancak pek az çalışmada geliştirilen çözümler matematiksel model çözümlerinde elde edilen sonuçlar ile karşılaştırılmaktadır. GSP için oldukça geniş bir kütüphane mevcut iken (TSPLIB) kütüphanede ÇGSP çözüm sonuçlarını içeren çok az sayıda veri kümesi bulunmaktadır. Üstel artan çözüm uzayı sebebi ile matematiksel modelin eniyi çözümlerine makul sürelerde ulaşılamamakla birlikte algoritmalar 1şı̆̆ında varılan sonuçların geçerliliğinin, matematiksel model sonuçları ile karşılaştırıldığında daha sağlıklı tespit edileceği de bir gerçekliktir. Bu çalışmada kullanılan algoritmaların etkinliği, matematiksel model sonuçları elde edilerek tartışılmıştır.

Çalışmaların çoğu ÇGSP çözümü için metasezgisel algoritmaların geliştirilmesine odaklanmaktadır. Metasezgisel algoritmaların karmaşık yapısı çözüm sürelerini olumsuz yönde etkilemektedir. Basit ve anlaşılır algoritmalar uygulanabilirlik ve çeviklik yönü ile daha avantajlıdır. ÇGSP, metasezgisel yerine daha basit sezgisel algoritmalar kullanılarak da iyi çözümler elde edilebilecek bir problemdir. Bu tür algoritmaların etkinliklerinin ölçülmesi ortaya konması gerekmektedir ki literatürde ilgili problem için az sayıda çalışma yer almaktadır.

ÇGSP, NP-zor bir problem türü olduğundan ilk ortaya çıktığından bu yana araştırmacılar tarafindan önem verilen bir problemdir. Uygulama alanı klasik gezgin satıcı probleminden daha fazla olmasına karşın henüz klasik gezgin satıcı problemi kadar üzerinde durulmamıştır.

Çalışmanın ikinci bölümünde önerilen çözüm yaklaşımı açıklanmıştır. Üçüncü bölümde deneysel çalışmalar ve sonuçları, son kısımda ise sonuç ve öneriler yer almaktadır. 


\section{Materyal ve Metot}

Üçlü Gezgin Satıcı Problemi (3 - GSP) çözümü kümeleme ve rotalama adımlarını içeren bir ardışık algoritma ile elde edilmiştir. Problemde ulaşılmak istenen amaç toplam maliyeti küçüklemek bunu yaparken de mümkün olduğunca dengeli bir dağıtım yapılmasını sağlamaktır. Noktalar birbirine olan uzaklıklarına göre üç farklı kümeye ayrılmıştır. Böylece her bir küme için üç farklı gezgin satıcı problemi elde edilmiş ve rotalar belirlenmiştir. Noktalar, k -ortalamalar yöntemi ile kümelenmiştir. Yöntem kolay anlaşılır olması ve hızlı sonuç vermesinin yanı sıra elde edilecek küme sayısı yani $\mathrm{k}$ değeri belirli olduğundan tercih edilmiștir. En Yakın Komşu Sezgiseli iyi bilinen bir tur oluşturucu, 2-opt algoritması ise tur iyileştirici bir algoritmadır. $\mathrm{Bu}$ iki yöntem ardışı olarak kullanıldıklarında çözümün kalitesinin iyileşmesi doğaldır.

Aşamalarda kullanılan $\mathrm{k}$ - ortalamalar, EYK ve 2 - opt yöntemlerinin zaman karmaşıkları sırası ile $O(n), O\left(n^{2}\right), O\left(n^{2.2}\right)$ olup polinomaldir. Günümüzde şartlar çok hızlı değişmekte ve değişen şartlara aynı hızda ayak uydurmak gerekmektedir. Eniyi çözümlerden ziyade yeterince iyi çözümlere daha hızlı ulaşmak günden günde önem kazanmaktadır. Çözümde kullanılan yöntemler problemin iki amaçlı yapısını desteklemesi ile birlikle bu bakış açısı da göz önüne alınarak tercih edilmiştir.

\subsection{Matematiksel Model}

ÇGSP'nin çözümü için toplam mesafenin en küçüklenmesi (MinSum) ve en uzun rotanın en küçüklenmesi (MinMax) olmak üzere iki farklı amaç fonksiyonuna sıklıkla başvurulmaktadır (Soylu, 2015).

MinSum amaç fonksiyonuna sahip yani kat edilen toplam mesafenin en aza indirilmesi son derece dengesiz çözümlere yol açabilmektedir (Necula vd. 2015). Bu nedenle ilgili amaç gerçek hayat uygulamaları için kullanışlı değildir. Bu çalışmada da önerilen yaklaşım sonucu elde edilen çözümler MinMax modeli çözümleri ile karşılaştırılarak yorumlanmıştır. İzleyen bölümde her iki amaç fonksiyonuna sahip modeller tanıtılacaktır. Modeller, üstel artan çözüm uzayına sahip olup NP- zor sınıfinda yer almaktadırlar.

ÇGSP, $G=(V, E)$ şeklinde temsil edilen yönlü bir $\mathrm{G}$ çizgesi olarak modellenmektedir. ( $\mathrm{V}=$ vertex, $\mathrm{E}=\mathrm{Edge}) \mathrm{Bu}$ ifadede $\mathrm{V}$ düğümler kümesi $\mathrm{E}$ ise, ayrıtlar kümesi olarak tanımlanır. $C=$ $\left(c_{i j}\right)$, E kümesi ile ilişkili olan maliyet matrisidir. İlgili problemde kullanılan $\mathrm{C}$ matrisi $c_{i j}=c_{j i}$ olup simetrik bir matristir. $x_{i j k}$, $(i, j, k)$ kenarı seçildiğinde 1 değerini aksi durumda 0 değerini alan ikil değişkendir. MinMax amaç fonksiyonuna sahip ÇGSP modeli verilmiştir (Necula,2015). Modelde birinci dügü̈m, merkez noktayı (depoyu) temsil etmektedir.

$$
\begin{array}{cl}
\sum_{j=2}^{n} x_{1 j k}=1 & k=1, \ldots, m \\
\sum_{j=2}^{n} x_{j 1 k}=1 & k=1, \ldots, m \\
\sum_{i=1}^{n} \sum_{k=1}^{m} x_{i j k}=1, & j=2, \ldots, n, i \neq j \\
\sum_{j=1}^{n} \sum_{k=1}^{m} x_{i j k}=1, & i=2, \ldots, n, i \neq j \\
\sum_{i=1}^{n} x_{i j k}=\sum_{i=1}^{n} x_{j i k}, & j=2, \ldots, n \\
u_{i}-u_{j}+(n-m) * x_{i j} & \leq n-m-1, \ldots, m, i \neq j \\
& 2 \leq i \neq j \leq n \\
\sum_{(i, j) \in A}^{n} c_{i j} x_{i j k} \leq T, & k
\end{array}
$$

Amaç fonksiyonu (1), en uzun turu enküçükler. Kısıt (2) m adet satıcının merkezden çıkış yapmış ve kısıt (3) m adet satııının merkeze dönmüş olmasını sağlar. (4) ve (5) her düğüme yalnızca bir kez gelinmesini ve bir kez çıkış yapılmasını sağlayan derece kısıtlarıdır. (7), Gavish (1976) tarafindan önerilen alttur eleme kısitıdir. (8) her bir satıcidan en uzun mesafe kat edeni $T$ değişkenine atar. Şekil 1'de TSPLIB kütüphanesinden alınan 22 şehirli Ulysses 22 veri setinin her iki amaç ile çözdürülmesi sonucu elde edilen rotalar verilmiştir. MinMax (EnbEnk) modeli araçların mesafelerini dengeleme amacı güderken toplam mesafeyi arttırmaktan kaçınmamaktadır. MinSum (EnkTop) amaç fonksiyonuna sahip olan model ise toplam mesafeyi azaltmak uğruna iş yükleri arasında önemli ölçüde farklar yaratmaktadır. Her iki amaca da ortak olarak hizmet eden bir çözüm yaklaşımının gerekliliği bu noktada kendini belli etmektedir.

$$
\text { EnkZ } \quad \sum_{(i, j) \in A} T
$$




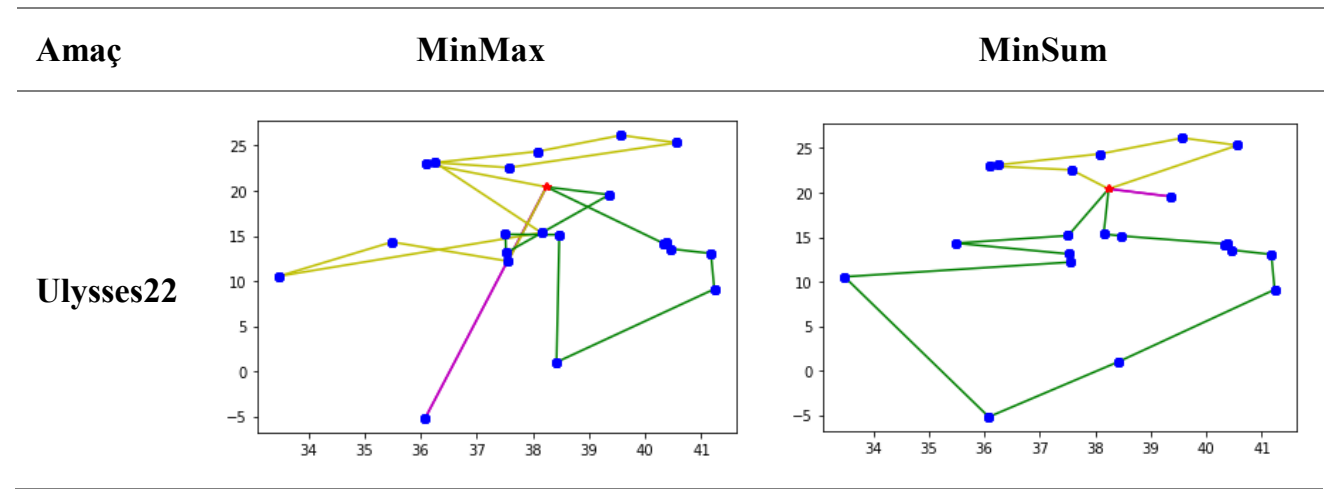

Şekil 1. MinMax ve MinSum Amaç Fonksiyonlarına Göre Matematiksel Model Sonuçlarına Ait Rotalar

\section{1. Önerilen Yöntem}

Bu çalışmada Çoklu Gezgin Satıcı Problemi, araç (satıcı) sayısının üç olduğu Üçlü Gezgin Satıcı Problemi olarak uyarlanmıştır ve yöntem üç araçlı problemler üzerinde test edilerek önerilmiştir. Şehirlerin aralarındaki uzaklıklara göre kümelenmesi ve elde edilen kümeler için ayrı ayrı rotaların hesaplanması adımlarını içeren iki aşamalı bir yöntem uygulanmıştır. Kümelerin elde edilmesi ile üçlü gezgin satıcı problemi, üç farklı tek-gezgin satıcı problemine dönüştürülerek tek-gezgin satıcı problemi için kullanılan çözüm algoritmalarının kullanılabilmesi sağlanmıştır. Bilimsel yazın incelendiğinde, ÇGSP çözümü için metasezgisel algoritmalara sıklıkla başvurulmuştur.

GSP çözümü için ise sezgisel, metasezgisel ve kesin çözüm yöntemleri olmak üzere birçok farklı yöntem üzerinde çalışılmıştır. Kesin çözüm yöntemlerinin büyük boyutlu problemlerde kullanılması mümkün değildir. Metasezgisel yöntemler daha karmaşık yapılı, uygulanabilirlik ve zaman tasarrufu yönü ile sezgisel yöntemlere göre dezavantajlıdır. İşbu çalışmada belirtilen hususlar dikkate alınarak En Yakın Komşu Sezgiseli ve 2 - opt algoritması çözümlerin elde edilmesi için kullanılmıştır. Şekil 2.'de yöntemin akış şeması verilmiştir.

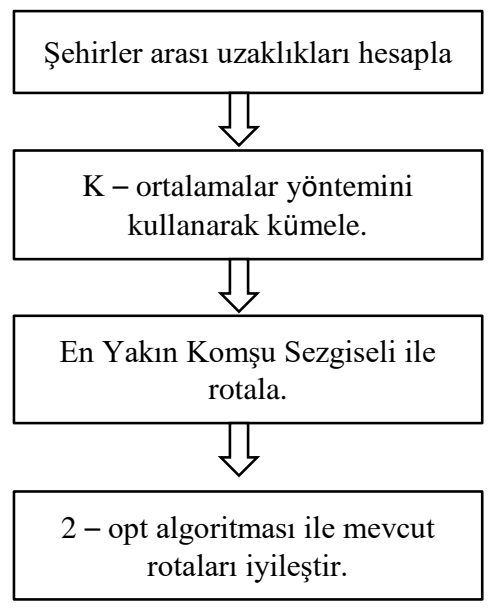

Şekil 2. Önerilen Yöntem Uygulama Adımları

Şekil 3.'te ise yöntemin aşamaları şekilsel olarak özetlenmiştir. TSPLIB kütüphanesinden alınan Bayg29 adlı veri setinde bulunan noktalar aralarındaki uzaklıklara göre k ortalamalar yöntemi ile kümelenmiştir. Veri setinde Şekil 3.a'da verilen 29 adet nokta bulunmakta olup 1. Nokta (kırmızı) merkez olarak belirlenmiştir. Her bir araç bu merkezden çıkacak ve turunu bitirerek merkeze geri dönecektir. 29 nokta 3 kümeye Şekil 3.b'deki gibi ayrılmıştır. Kümeler için rotalar ayrı ayrı En Yakın Komşu sezgiseli uygulanarak inşa edilmiş daha sonra 2 - opt algoritmasının uygulanmasıyla rotalar toplam maliyeti düşürecek şekilde iyileştirilmiştir. Yöntem sonucu elde edilen rotalar Şekil 3.c'de verilmiştir.

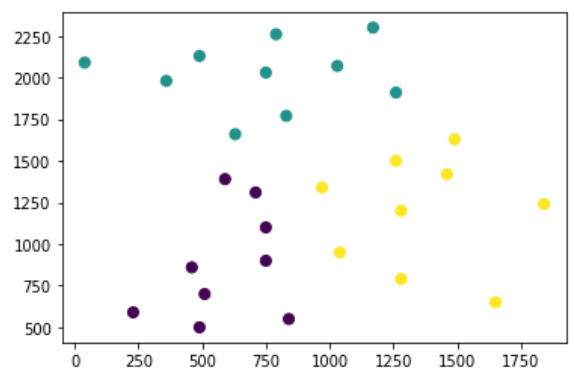

(a)

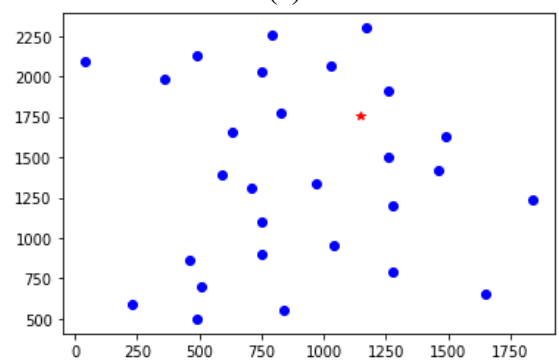

(b)

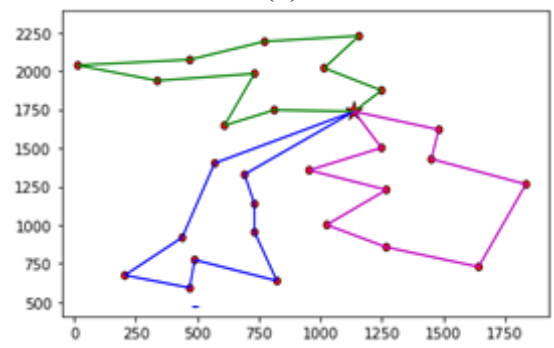

(c)

Şekil 3.a Depo ve uğrak noktaları, 3.b Kümeleme, 3.c Rotalama (Enyakın komşu ve 2-opt) 


\section{Araştırma Sonuçları ve Tartışma}

ÇGSP üzerinde yapılan çalı̧̧maların çoğu metasezgisel çözüm yöntemlerinin geliştirilmesine ve varılan sonuçların yine diğer metasezgisel çözümlerle karşılaştırılmasına odaklanmaktadır. Bu çalışmada ÇGSP'nin bir alt kümesi olan ÜGSP için sonuçlar MinMax modelinin ürettiği ve önerilen iki aşamalı sezgisel yönteminin ürettiği sonuçlar ile karşılaştırılmıştır. Literatürden ve gerçek hayat uygulama amaçlarından yola çıkılarak, karşılaştırma kriterleri, toplam rota uzunluğu, en uzun rota değeri ve çözüm süresi olarak belirlenmiştir.

ÇGSP yıllar boyunca araştırmacıların üzerinde çalıştığ 1 , kullanım alanı oldukça geniş, GSP'nin genişletilmiş ve daha zor versiyonu olan bir problem olmasına karşın kıyaslama problemlerinin mevcut olduğu TSPLIB gibi bir kütüphaneye sahip değildir. Necula vd. (2015) çalı̧̧malarında TSPLIB kütüphanesinden seçilmiş 4 veri setine ait ÇGSP sonuçlarını MTSPLIB kütüphanesi olarak paylaşmışlardır. Bunun yanı sıra çözüm sürelerinin sağlıklı karşılaştırılabilmesi adına 20 boyutlu 10 adet rassal veri kümesi türetilerek deneyler yapılmıştır. Kullanılan tüm örnekler $\mathrm{x}$ ve y koordinatlarını içermektedir ve şehirlerarası uzaklıklar Öklid uzaklık formülü ile hesaplanmıştır.

Çözüm yönteminde kullanılan ardışık algoritmalar PYTHON programlama dilinde, matematiksel modeller GUROBI optimizasyon programında yazılmış, Intel ${ }^{\circledR}$ Core ${ }^{\mathrm{TM}}$ i5 -8400 CPU 2.80GHz, 16 GB RAM özelliklerinde bir bilgisayar kullanılarak çalıştırılmıştır.
Tablo 1. MTSPLIB Test Problemleri Sonuçları

\begin{tabular}{|c|c|c|c|c|c|}
\hline \multirow[b]{2}{*}{$\begin{array}{l}\text { Problem } \\
\text { Adı }\end{array}$} & \multirow[b]{2}{*}{$\mathbf{m}$} & \multicolumn{2}{|c|}{ Optimum } & \multicolumn{2}{|c|}{$\begin{array}{c}\text { K-ort } \rightarrow \text { EYK } \rightarrow 2 \text { - } \\
\text { OPT }\end{array}$} \\
\hline & & $\begin{array}{c}\text { Maks } \\
\text { Tur }\end{array}$ & $\begin{array}{l}\text { Toplam } \\
\text { Tur }\end{array}$ & $\begin{array}{c}\text { Maks } \\
\text { Tur }\end{array}$ & $\begin{array}{c}\text { Toplam } \\
\text { Tur }\end{array}$ \\
\hline Eil51 & 3 & 159.57 & 477.15 & 176.15 & 505.25 \\
\hline Berlin52 & 3 & 3244.37 & 9591.15 & 3504.56 & 9098.77 \\
\hline Eil76 & 3 & 197.34 & 587.65 & 291.89 & 691.88 \\
\hline Rat99 & 3 & 597.55 & 1780.48 & 735.77 & 1732.22 \\
\hline
\end{tabular}

Tablo 1'de sonuçlar optimum çözümler ve önerilen yöntem çözümlerine göre sütunlara ayrılmıştır. Her bir yönteme göre bulunan en uzun tur ve toplam tur değerleri tabloda paylaşılmıştır. Literatürden alınan test problem sonuçları incelendiğinde önerilen yaklaşımın optimum çözümlere önemli bir düzeyde yakınsadığı görülmektedir. Şekil 4.'te Rat99 isimli örneğe ait rotalar verilmiştir. Önerilen yöntemin etkinliği görsel olarak da desteklenmektedir.

K - ort, EYK ve 2 - opt algoritmalarının ardışık olarak uygulanması ile geliştirilen yöntemin daha iyi test edilmesi adına rassal test problemleri üretilmiş ve çözümler belirlenen performans kriterlerine göre kutu grafikleri kullanılarak analiz edilmiştir. Problemlerde kullanılmak üzere türetilen veriler Mendeley Data (2021)'da yer almaktadır. 20 noktadan meydana gelen 10 adet rassal problem 3 satıcıl problemler için çözdürülmüştür. Her bir tur için tur uzunlukları model ve önerilen sezgisel yöntem için kaydedilerek Tablo 2'de özetlenmiştir. Rassal problemler koordinatları 0 ve 100 aralı̆ğında noktalar türetilerek oluşturulmuştur. Belirli bir sınırda üretilen noktalar ile yöntemin geçerliliği daha net bir şekilde ortaya koyulmuştur.

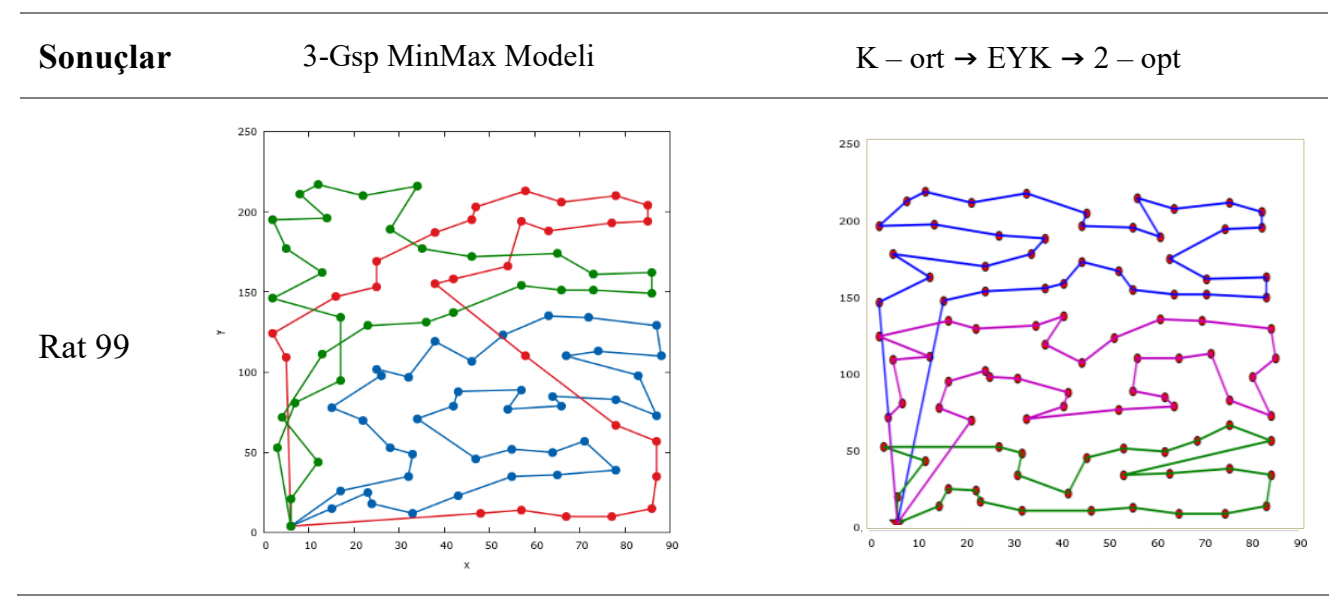

Şekil 4. Rat 99 Veri Setine Ait Çözümlerin Görselleștirilmesi

Kutu grafikleri, ç̧̈züm süresi, toplam tur uzunluğu ve en uzun tur uzunluğu olmak üzere 3 kritere göre düzenlenmiştir (Şekil 5). En uzun tur kriteri göz önüne alındığında sezgisel yöntem model çözümlerine yakın çözümler vermektedir. Diğer iki kıstas için ise sezgisel yöntemin daha iyi olduğu görülmektedir. Özellikle çözüm süresi yönü ile sezgisel yöntemin performansı açık ara öndedir. Neredeyse çözümlerin tamamında, problem boyutu fark etmeksizin 1 saniye ve altındaki sürelerde erişebilmektedir. Model çözüm süreleri ise büyük dengesizlikler içermekte olup 20 boyutlu küçük bir problem için dahi eniyi çözümlere ulaşmak saatler alabilmektedir. Toplam tur uzunluğu bir diğer önemli kriter olup, toplam maliyet ile ilişkilendirilmektedir. Toplam maliyetin daha az olması, toplam tur uzunluklarından kaynaklanan dengesizliklerin göz ardı edilmesi için önemli bir etkendir. Şöyle ki satıcı iş yüklerinin dengeli olarak dağıtılmaması istenmeyen bir durumdur ancak bu dengesizlik toplam maliyette bir azalma sağlıyorsa belirli bir noktaya kadar göz ardı edilebilmektedir. $\mathrm{Bu}$ noktada karar vericilerin tercihleri ön plana çıkmaktadır. 
Tablo 2. Rassal Problem Sonuçlart

\begin{tabular}{|c|c|c|c|c|c|c|}
\hline Problem No & Yöntem & Tur 1 & Tur 2 & Tur 3 & Toplam Tur & Süre(sn) \\
\hline \multirow{2}{*}{1} & Model & 211.7905 & 211.1438 & 208.2997 & 631.2341 & 605 \\
\hline & Sezgisel & 176.5414 & 221.6037 & 201.3994 & 599.544 & 0.4893 \\
\hline \multirow{2}{*}{2} & Model & 182.7294 & 172.8836 & 180.042 & 535.6554 & 41.67 \\
\hline & Sezgisel & 105.7372 & 242.1948 & 159.8891 & 507.8212 & 0.307 \\
\hline \multirow{2}{*}{3} & Model & 237.4384 & 226.8164 & 236.9967 & 701.2516 & 304.30 \\
\hline & Sezgisel & 238.0671 & 273.1429 & 156.6330 & 667.8431 & 1.143 \\
\hline \multirow{2}{*}{4} & Model & 200.1838 & 202.399 & 198.103 & 600.686 & 5821 \\
\hline & Sezgisel & 218.186 & 159.255 & 197.788 & 575.229 & 0.4259 \\
\hline \multirow{2}{*}{5} & Model & 175.088 & 179.00 & 181296 & 535.3864 & 47.10 \\
\hline & Sezgisel & 197.7274 & 179.1301 & 126.380 & 503.2381 & 0.4393 \\
\hline \multirow{2}{*}{6} & Model & 241.4277 & 241.906 & 242.012 & 725.3471 & 3387.44 \\
\hline & Sezgisel & 272.7663 & 205.408 & 201.3994 & 659.4779 & 0.2519 \\
\hline \multirow{2}{*}{7} & Model & 192.7258 & 192.2680 & 189.2680 & 574.0202 & 255.08 \\
\hline & Sezgisel & 198.6717 & 181.1771 & 152.8301 & 532.6790 & 0.2934 \\
\hline \multirow{2}{*}{8} & Model & 203.4266 & 202.004 & 202.5170 & 607.9480 & 175.19 \\
\hline & Sezgisel & 208.9451 & 171.9946 & 212.0097 & 592.9495 & 1.8690 \\
\hline \multirow{2}{*}{9} & Model & 217.0402 & 225.3017 & 225.8364 & 668.1785 & 1270.87 \\
\hline & Sezgisel & 283.7221 & 168.3822 & 137.6670 & 589.7714 & 0.3208 \\
\hline \multirow{2}{*}{10} & Model & 196.2201 & 194.3825 & 190.7895 & 581.3921 & 1372.77 \\
\hline & Sezgisel & 161.5491 & 176.0029 & 196.4391 & 533.9886 & 1.2883 \\
\hline
\end{tabular}

En Uzun Tur

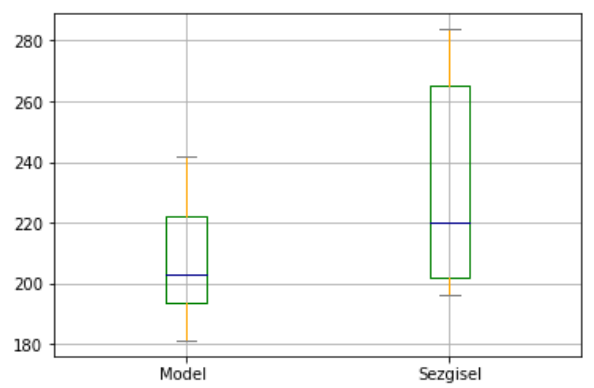

Çözüm Süresi

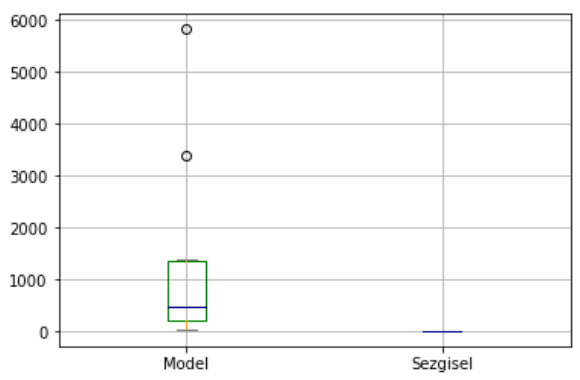

Toplam Mesafe

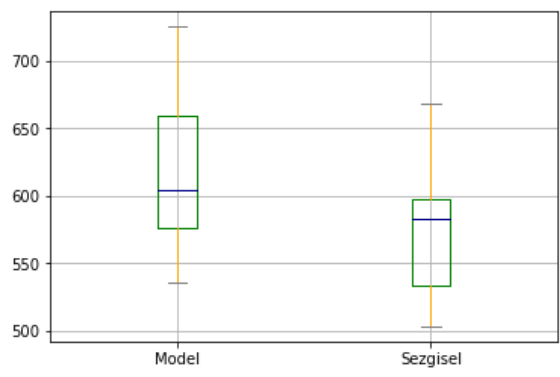

Şekil 5. 20 boyutlu Rassal Problem Çözümleri için Kutu Grafikleri

\section{Sonuç}

Çözümlerin değerlendirilmesi aşamasında üç kriter seçilmiştir. $\mathrm{Bu}$ kriterlerden ilki karşılaştırma yapılan matematiksel modelin amaç fonksiyonu olan en uzun turun enküçüklenmesi dolayısı ile turların her bir gezgin satıcı için dengeli dağıtılabilmiş olmasıdır. Geliştirilen yöntem sonuçları bu kritere göre değerlendirildiğinde optimum çözümlere yaklaşık olarak \%70-80 civarlarında yakınsadığı görülmüştür ki bu problem boyutu ve yapısı göz önüne alındığında oldukça iyi bir orandır. Medyan değer esas alındığında bu yaklaşım \%90'dır. Bir diğer ölçüt ise toplam mesafe olarak seçilmiştir. Toplam mesafe maliyeti etkileyen önemli bir husustur. Model doğası gereği turları dengelemeye çalışırken toplam mesafeyi artırmaktadır ki bu istenmeyen bir durumdur. İki aşamalı algoritma, bu ölçüt için örnekler problemlerin büyük bir kısmında daha iyi sonuçlar vermiştir. Satıcı iş yükleri arasındaki dengesizlik toplam maliyetin azalması olarak çözümlere yansımıştır. Karşılaştırmada dikkate alınan son ölçüt ise çözüm süresidir. Tüm aşamaların tek bir çalıştırılmada gerçekleştirildiği algoritmada çözümler 1 saniye gibi oldukça kısa sürelerde elde edilmiştir. Yöntem bu yönü ile e-ISSN: 2148-2683 matematiksel model çözüm süresi ile kıyaslanamayacak kadar iyi performans sergilemiştir.

Burada iki amaçlı 3-GSP için elde edilen sonuçların, m-GSP için genelleştirilmesinin önünde görünen hiçbir engel mevcut değildir. İzleyen çalışmalarda deneylerle etkinliği ortaya koyulabilir.

\section{Kaynakça}

Al-Furhud, M. A., \& Ahmed, Z. H. (2020). Genetic algorithms for the multiple travelling salesman problem. International Journal of Advanced Computer Science and Applications (IJACSA), 11(7), 553-560.

Angel, R. D., Caudle, W. L., Noonan, R., \& Whinston, A. N. D. A. (1972). Computer-assisted school bus scheduling. Management Science, 18(6), B-279.

Bektas, T. (2006). The multiple traveling salesman problem: an overview of formulations and solution procedures. Omega, 34(3), 209-219.

Carter, A. E. (2003). Design and application of genetic algorithms for the multiple traveling salesperson assignment problem (Doctoral dissertation, Virginia Tech). 
Croes, G. A. (1958). A method for solving traveling-salesman problems. Operations research, 6(6), 791-812.

Dantzig, G. B., \& Ramser, J. H. (1959). The truck dispatching problem. Management science, 6(1), 80-91.

Gavish, B. (1976). Note - a note on "the formulation of the msalesman traveling salesman problem". Management Science, 22(6), 704-705.

Gilbert, K.C. \& Hofstra, R.B. (1992). A new multiperiod multiple traveling salesman problem with heuristic and application to a scheduling problem. Decision Sciences, Vol. 23, pp.250-9.

Gorenstein, S. (1970). Printing press scheduling for multi-edition periodicals. Management Science, 16(6), B-373.

Gunesen, Beyza (2021), "Data For: Euclidean Matrix", Mendeley Data, V1, doi: 10.17632/rvv4ymck92.1

Huang, Z. (1998). Extensions to the k-means algorithm for clustering large data sets with categorical values. Data mining and knowledge discovery, 2(3), 283-304.

K. Helsgaun. An Effective Implementation of the Lin-Kernighan Traveling Salesman Heuristic,Department of Computer Science, Roskilde University.

Kara, I., \& Bektas, T. (2006). Integer linear programming formulations of multiple salesman problems and its variations. European Journal of Operational Research, 174(3), 1449-1458.

Laporte, G. \& Nobert, Y. (1980). A cutting planes algorithm for the m-salesmen problem. Journal of the Operational Research Society, Vol. 31, pp.1017-23.

Latah, M. (2016). Solving multiple TSP problem by K-means and crossover based modified ACO algorithm. International Journal of Engineering Research and Technology, 5(02).

Liu, W., Li, S., Zhao, F., \& Zheng, A. (2009, May). An ant colony optimization algorithm for the multiple traveling salesmen problem. In 2009 4th IEEE conference on industrial electronics and applications (pp. 1533-1537). IEEE.

Matai, R., Singh, S. P., \& Mittal, M. L. (2010). Traveling salesman problem: an overview of applications, formulations, and solution approaches. Traveling salesman problem, theory and applications, 1 .

Matsuura, T., \& Numata, K. (2014, September). Solving min-max multiple traveling salesman problems by chaotic neural network. In International Symposium on Nonlinear Theory and its Applications.

Miller, C.E.; Tucker, A.W. \& Zemlin, R.A.(1960). Integer programming formulation of traveling salesman problems. Journal of Association for Computing Machinery, Vol. 7, pp. 326-9.

Na, S., Xumin, L., \& Yong, G. (2010, April). Research on k-means clustering algorithm: An improved k-means clustering algorithm. In 2010 Third International Symposium on intelligent information technology and security informatics (pp. 63-67). Ieee.

Nallusamy, R., Duraiswamy, K., Dhanalaksmi, R., \& Parthiban, P. (2010). Optimization of non-linear multiple traveling salesman problem using k-means clustering, shrink wrap algorithm and meta-heuristics. International Journal of Nonlinear Science, 9(2), 171-177.

Necula, R., Breaban, M., \& Raschip, M. (2015, November). Tackling the bi-criteria facet of multiple traveling salesman problem with ant colony systems. In 2015 IEEE 27th International Conference on Tools with Artificial Intelligence (ICTAI) (pp. 873-880). IEEE.

Necula, R., Raschip, M., \& Breaban, M. (2018). Balancing the subtours for multiple TSP approached with ACS: Clustering- based approaches vs. MinMax formulation. In EVOLVE-A Bridge between Probability, Set Oriented Numerics, and Evolutionary Computation VI (pp. 210-223). Springer, Cham.

Singh, A. (2016). A review on algorithms used to solve multiple travelling salesman problem. International Research Journal of Engineering and Technology (IRJET), 3(4), 598-603.

Soylu, B. (2015). A general variable neighborhood search heuristic for multiple traveling salesmen problem. Computers \& Industrial Engineering, 90, 390-401.

Svestka, J.A. \& Huckfeldt, V.E. (1973). Computational experience with an m-salesman traveling salesman algorithm. Management Science, Vol. 19, No. 7, pp. 790-9.

Tiong, W. K. (2007). A Comparison between Heuristic and MetaHeuristic Methods for Solving the Multiple Traveling Salesman Problem. International Journal of Mathematical and Computational Sciences, 1(1), 13-16. 